\title{
A small rainfall simulator for the determination of soil erodibility
}

\begin{abstract}
A. Kamphorst
Department of Soil Science and Plant Nutrition, Wageningen Agricultural University, P.O. Box 8005, NL 6700 EC Wageningen, Netherlands
\end{abstract}

Received 15 April 1987; accepted 10 May 1987

Key words: rainfall simulator, soil erodibility, soil conservation, soil loss, runoff, infiltration

\begin{abstract}
A small rainfall simulator is described, which can be used in the field as well as in the laboratory for the determination of the water infiltration and erosion characteristics of soils. It is particularly suitable for soil conservation surveys, as it is light to carry and easy to handle in the field.

A description is given of a standard procedure for the determination of topsoil erodibilities in the field. Some results obtained with the standard procedure are presented. The method appears to be highly sensitive for soil properties influencing soil erodibility, such as clay content, organic matter content and soil $\mathrm{pH}$.
\end{abstract}

\section{Introduction}

The soil erodibility factor or K-factor in the universal soil loss equation is a soil parameter representing the integrated effect of the infiltration characteristics and of soil particle detachability and transportability (Römkens, 1985). Together with the rainfall erosion factor and factors for slope steepness, slope length, vegetation cover and soil management, it determines the erosion hazard or predicted annual soil loss in a particular field location (Wischmeier \& Smith, 1960).

The soil erodibility factor cannot be estimated simply on the basis of measurable or observable environmental variables. It has to be determined experimentally for every individual soil series by making elaborate soil loss measurements in unit field plots (Wischmeier \& Smith, 1978).

To avoid the expensive and time-consuming measurements in field plots, many field workers have tried to predict soil erodibility ratings from the results of more simple laboratory and field tests. These tests range from the physical, chemical and mineralogical analysis of the soil (Wischmeier et al., 1971; Roth et al., 1974), through determinations of certain aspects of the physical reaction of the topsoil ma- 
terial (Bergsma \& Valenzuela, 1981; Bryan, 1969; Low, 1954), to measurements of the infiltration rate, runoff and soil loss with infiltrometers and rainfall simulators (Adams et al., 1957; Meyer \& McCune, 1958; Bergsma \& Kamphorst, 1986).

Measuring soil loss and runoff under simulated rainfall is by far the most promising method to obtain a quantitative rating of the erodibility of different soils. Theoretically this method has the advantage that the recorded runoff and soil loss reflect the integrated effect of all the processes occurring during sheet erosion, i.e., splash, swelling, slaking, crusting and sealing, infiltration and runoff, particle detachment and sediment transport.

Most rainfall simulators presently in use offer the possibility to vary and regulate the duration, intensity, drop size distribution and kinetic energy of the showers produced. Due to this they are rather large and difficult in transport and operation, the more so as they are generally designed for a plot size of $0.5 \mathrm{~m}^{2}$ or more.

In soil conservation projects it is necessary to determine the soil erodibility for many different soil series and one often wants to investigate the effect of different soil management practices on this erodibility. Moreover, due to the spatial variability of soil conditions the simulation has to be repeated 4 to 8 times in each soil or management unit (Kamphorst \& Bergsma, 1986). Under such conditions the field surveyor requires a simulator that can be transported and operated easily.

This paper describes a small and simple rainfall simulator, designed specifically for soil conservation surveys, which can be transported even by a surveyor on a bycicle. It is the smallest of a series of simulators developed at Wageningen Agricultural University. The simulator is completely standardized, so that the results of measurements obtained on a particular soil or management unit can be compared with results produced elsewhere. This will also open the possibility to relate the results obtained with the simulator to K-factors determined with standard field plots in different parts of the world.

\section{Description of the simulator and its operation in the field}

With the rainfall simulator one measures the runoff and soil loss generated by a standardized rainshower on a plot with a standard slope and surface area. The duration, intensity and kinetic energy of the shower is such that a high sensitivity of the test results for differences in soil properties is obtained. Table 1 lists the specifications of the standard apparatus.

Essentially the simulator consists of three parts, as is shown in Figs. 1 and 2:

- a sprinkler with a built-in pressure regulator, based on the Mariotte bottle principle, for the production of the standard rain shower (A in Fig. 1).

- A support for the sprinkler, which also functions as a wind shield in the field (B)

- a stainless steel frame, which is hammered into the soil and is meant to prevent the lateral movement of water from the test plot to the surrounding soil. Attached to the plot frame is a gutter for the removal of the runoff and soil-loss to a sample bottle (C).

The sprinkler consists of a calibrated cylindrical water reservoir (a in Fig. 1) with a capacity of approximately $1200 \mathrm{ml}$, which is in open connection with the sprin- 
Table 1. Specifications of the rainfall simulator.

Magnitude of rainshower

Duration of rainshower

Intensity of rainshower

Fall height of drops at top of slope

Fall height of drops at bottom of slope

Average fall height of drops

Diameter of drops

Mass of drops

Number of capillary tubes

Kinetic energy of shower

Surface area of test plot

Slope of test plot
$18 \mathrm{~mm}$
$3 \mathrm{~min}$
$6 \mathrm{~mm} / \mathrm{min}$
$375 \mathrm{~mm}$
$425 \mathrm{~mm}$
$400 \mathrm{~mm}$
$5.9 \mathrm{~mm}$
49
$35.4 \mathrm{~J} / \mathrm{mm}$
$20 \%$

$0.106 \mathrm{~g}$

$0.0625 \mathrm{~m}^{2}$

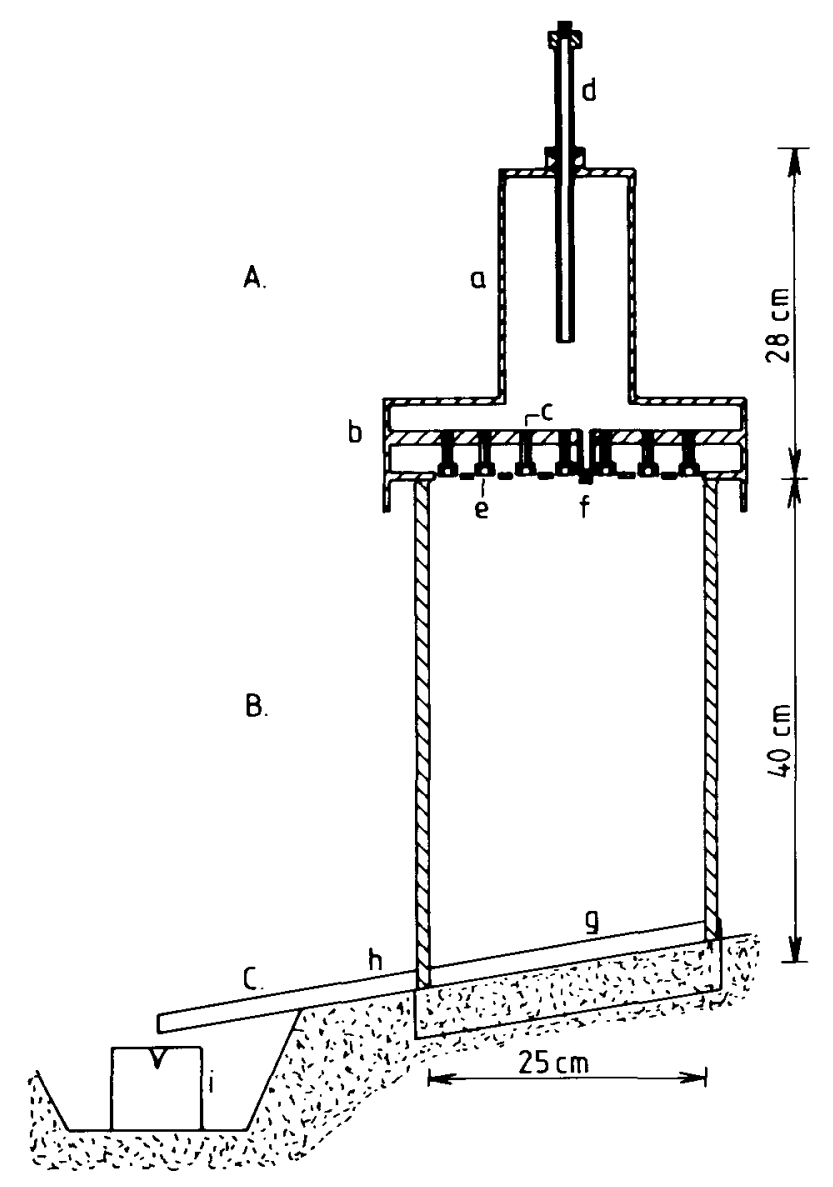

Fig. 1. Vertical cross-section of the rainfall simulator. 


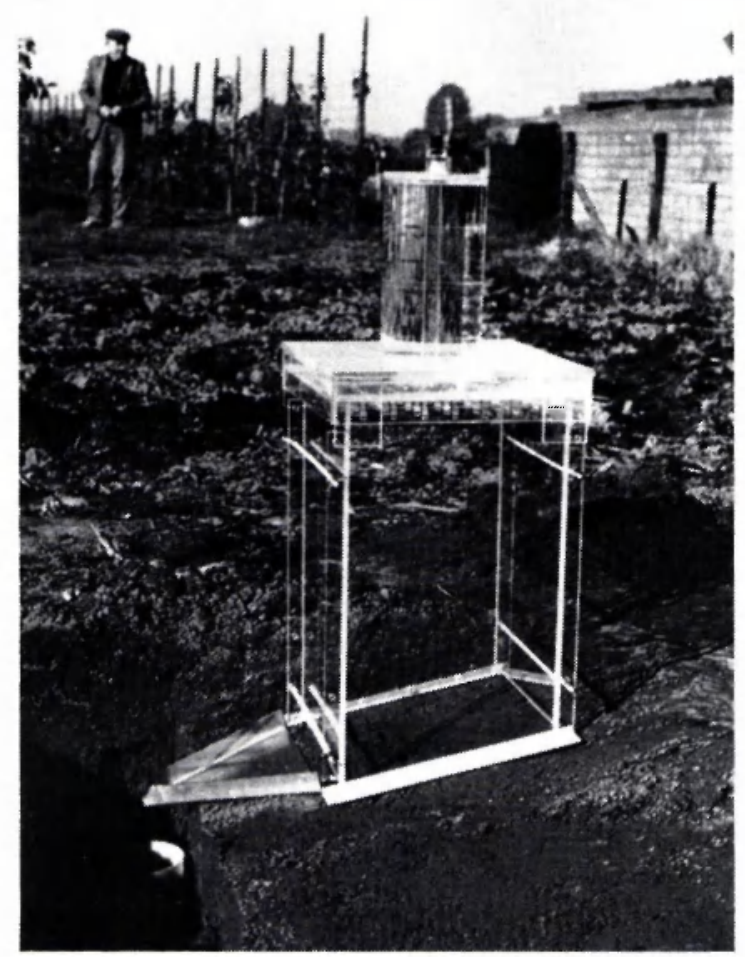

Fig. 2. Use of the rainfall simulator in the field.

kling head (b). Water is discharged from the sprinkling head through 49 capillaries (c). The discharge rate is determined by the length and the inner diameter of these capillaries.

The pressure head on the capillaries can be increased or decreased by moving the aeration tube (d) upward or downward. The magnitude of this pressure head regulation is sufficient to correct for the influence of the viscosity of the water used on the discharge rate of the capillaries. Hence it is not meant to be used for the production of showers of different intensities but to control the intensity of the standard shower required. The lower ends of the capillaries are fitted with a short piece of tubing (e). The inner and outer diameters of this tubing control the drop size and hence the drop frequency.

Before filling the sprinkler with water, a plot with a slope of $20 \%$ is prepared with the aid of a spade. The slope length should be at least $0.4 \mathrm{~m}$, to accommodate both the test plot and the gutter. At the bottom of the slope a small trench is made, in which the sample bottle for the collection of runoff and soil-loss is placed (see Fig. 2).

The support is placed on the plot, to check that the latter has the required slope of 
$20 \%$ and is level in the direction perpendicular to the direction of the slope. If these requirements are fulfilled, the upper rims of the support are all horizontal, which can be checked with a simple level instrument.

Adjoining to the testplot an auxiliary plot is made, which is used for filling the sprinkler with water. Also on this plot the support serves to check that the slopes are correct. Then the aeration pipe is closed with a cork and the sprinkler is placed upside down on the support. The cork on the filling pipe (f) is removed and the sprinkler is filled with water by using a funnel. During this operation air escapes through the capillaries.

After filling the sprinkler, the cork on the filling opening is replaced and the sprinkler is turned around to its sprinkling position on the auxiliary plot. Sprinkling starts when the cork on the aeration pipe is removed and can be stopped at any time by replacing this cork. To check that the sprinkler has the required discharge rate of $375 \mathrm{ml}$ per minute, a watch and the calibration on the water reservoir are used. To correct the discharge rate the aeration tube is moved upward or downward.

To carry out the actual test, the sprinkler is refilled and moved with the support to the test plot. After it is ascertained that the plot frame ( $\mathrm{g}$ in Fig. 1), gutter (h) and sample bottle (i) are in place, the water level in the reservoir is noted and the simulation is started by removing the cork from the aeration pipe.

During the simulation the sprinkling head is moved sideways in all horizontal directions, to make sure that the drops emerging from the capillaries are equally and randomly distributed over the test plot. This can be done by hand, as the sprinkling head slides easily on the upper rim of the support over predetermined distances.

After three minutes the simulation is stopped by replacing the cork on the aeration pipe. Sediment left behind in the gutter is added to the contents of the sample bottle with the aid of a wiper. The sample bottles are taken to the laboratory, where the amounts of runoff and sediment are determined by weighing and drying.

\section{Standard procedure for soil erodibility studies}

To obtain reproducible results, not only the simulation technique but also the selection and pretreatment of the test plots should be standardized. The main factors affecting the test results are the initial soil structure and the initial moisture content of the topsoil.

The soil structure is first of all influenced by the past and present land use. Therefore, the standard test should be carried out under a prescribed land use system, for which cropland under the most common rotation of annual crops in the area has been selected. However, the structure of the topsoil in this cropland changes during the year. For the rainfall simulation, which is carried out at one particular moment, it is recommended to use unploughed fallow plots during the wettest season. Under these conditions the surface soil is most vulnerable to erosion, because there has been ample opportunity for slaking in depth and swelling after the last tillage operations. Moreover, this condition also offers the best chance to find the soil at the standard moisture condition prescribed, i.e. at a moisture content near to field capacity. 


\section{A. KAMPHORST}

If it is not possible to carry out the test at a time when the moisture content is near to field capacity, it is recommended to carry out a prewetting treatment. This involves the determination of the volumetric moisture content at $\mathrm{pF}=2$ in an undisturbed core sample, followed by a determination of the actual moisture content in a core sample taken shortly before the test is carried out. As it was found that the infiltration front generally does not penetrate beyond a depth of approximately 50 mm during the test, the amount of water to be added for prewetting (in $\mathrm{ml}$ ) is estimated by multiplying the difference between the moisture content at $\mathrm{pF}=2$ and the actual moisture content (both expressed as a volume fraction) by a factor $5(\mathrm{~cm})$ and a factor $625\left(\mathrm{~cm}^{2}\right)$. The water is applied carefully enough to avoid splash and slowly enough to prevent water saturation of the soil surface and runoff. For this operation a small plastic container with a perforated lid is used. The water discharge from this container is regulated by pushing with the thumbs on the bottom of soft plastic, while holding the perforated lid close to the soil surface.

As was described earlier, the required $20 \%$ slope of the test plot is made with a spade. During this treatment, surface crusts initially present on the soil are removed. This means that the test results will incorporate the sealing effect of any crusts formed during the simulated rain shower.

During the shaping of the slope with a spade, smearing may occur. To open up the natural soil pores below the smeared surface, a thin layer of soil material is removed with the point of a knife or spatula. The loose material produced by this operation is carefully removed with a soft brush.

\section{Field results}

Table 2 presents the results obtained for different soils in the Netherlands, following as much as possible the standard procedure described above. The data for runoff, soil loss and sediment concentration, which are the averages of 8 repetitions, show that the soil loss recorded on these soils ranges between 4.1 and $46.8 \mathrm{~g}$ and that also the runoff and sediment concentration vary widely between different soils. To indicate the discriminating power of the test, the results of a statistical analysis of the soil loss, runoff and sediment concentration measurements, following Duncan's Multiple Range Test (Gomez \& Gomez, 1984), are presented in Table 3.

The most serious water erosion problems in the Netherlands are found in the rolling loess landscape in the province of Limburg. Due to past erosion the natural clay illuviation horizons in these soils are locally exposed at the soil surface. This has caused a variation of clay contents in the plough layers, ranging from $10 \%$ in the non-eroded soils to more than $30 \%$ in the strongly eroded soils.

The rainfall simulator was used to investigate the influence of the clay content on the erodibility of the loess soils, following as much as possible the standard procedure. A more detailed description of the procedures and results of these investigations, of which the rainfall simulation was only a part, will be presented in a subsequent paper (Oostrom \& Kamphorst, in prep.). Here some of the results are shown to illustrate the sensitivity of the test to differences in soil properties. Each point sbown in Fig. 3a represents the mean value of the results of 8 measurements. 
Table 2. Average runoff, soil loss and sediment concentration measured with the standard procedure on different soils in the Netherlands.

\begin{tabular}{|c|c|c|c|c|c|c|}
\hline Soil & Clay (\%) & $\begin{array}{l}\text { Organic } \\
\text { matter } \\
(\%)\end{array}$ & $\mathrm{pH}(\mathrm{KCl})$ & $\begin{array}{l}\text { Runoff } \\
\text { (ml) }\end{array}$ & $\begin{array}{l}\text { Soil loss } \\
\text { (g) }\end{array}$ & $\begin{array}{l}\text { Sediment } \\
\text { concentration } \\
(\mathrm{g} / \mathrm{l})\end{array}$ \\
\hline Aeolean sand & 0.5 & 2.8 & 3.7 & 641 & 17.1 & 27 \\
\hline Aeolean loamy sand & 0.0 & 1.0 & 5.4 & 806 & 35.0 & 43 \\
\hline Acolean sandy loam & 2.2 & 2.4 & 5.8 & 864 & 40.1 & 46 \\
\hline Coarse loess & 11 & 1.7 & 6.8 & 822 & 39.4 & 48 \\
\hline Medium loess & 18 & 1.6 & 6.3 & 677 & 18.0 & 27 \\
\hline Fine loess & 31 & 2.7 & 6.8 & 457 & 8.3 & 18 \\
\hline Riverine sandy loam & 16 & 3.0 & 6.6 & 322 & 5.2 & 16 \\
\hline Riverine clay loam & 27.9 & 6.6 & 5.2 & 692 & 4.8 & 7 \\
\hline Riverine clay & 51.7 & 13.5 & 5.2 & 465 & 4.1 & 9 \\
\hline
\end{tabular}

$\mathrm{pH}(\mathrm{KCl}), \mathrm{pH}$ measured in a $1 \mathrm{~mol} / \mathrm{l} \mathrm{KCl}$ extract.

Table 3. Results of Duncan's Multiple Range Test*.

\begin{tabular}{|c|c|c|c|c|c|c|}
\hline \multirow[t]{2}{*}{ Soil } & \multicolumn{2}{|l|}{ Runoff } & \multicolumn{2}{|l|}{ Soil loss } & \multicolumn{2}{|c|}{ Sediment concentration } \\
\hline & $P<0.05$ & $P<0.01$ & $P<0.05$ & $P<0.01$ & $P<0.05$ & $P<0.01$ \\
\hline Aeolean sand & $\mathrm{b}$ & c & $\mathrm{c}$ & $\mathrm{b}$ & $\mathrm{b}$ & b \\
\hline Aeolean loamy sand & a & $a b$ & b & a & $\mathrm{a}$ & $\mathrm{a}$ \\
\hline Aeolean sandy loam & $\mathrm{a}$ & a & a & a & a & a \\
\hline Coarse loess & $\mathrm{a}$ & $a b$ & $a b$ & a & a & a \\
\hline Medium loess & $\mathrm{b}$ & c & $\mathrm{c}$ & $b$ & b & $b$ \\
\hline Fine loess & c & d & d & c & c & $\mathrm{c}$ \\
\hline Riverine sandy loam & $\mathrm{d}$ & $\mathrm{e}$ & $\mathrm{d}$ & $\mathrm{c}$ & $\mathrm{c}$ & $\mathrm{cd}$ \\
\hline Riverine clay loam & b & $\mathrm{bc}$ & d & $\mathrm{c}$ & d & $\mathrm{e}$ \\
\hline Riverine clay & c & $\mathrm{d}$ & d & c & d & de \\
\hline
\end{tabular}

* Soils that have a letter in common in a particular column do not differ significantly at the probability level shown above the column.

Cultivation measures propagated and applied to reduce surface erosion of the loess soils are, amongst others, the application of lime and organic manures. The long-term effects of these practices could be studied in field trials where different amounts of lime and organic manures had been applied during the least 15 years. Fig. 3b shows the effect of different lime applications, as expressed in the $\mathrm{pH}(\mathrm{KCl})$ values of the topsoils, on the soil loss measured with the rainfall simulator. Fig. $3 \mathrm{c}$ indicates how the soil loss is also influenced by differences in the organic matter content of the soil. In Fig. $3 \mathrm{~b}$ each point represents the result of one simulation run, whereas in Fig. 3c the results shown are the mean values of eight replications.

\section{Acknowledgements}

The author expresses his appreciation for the contributions of his students E.M.F. 

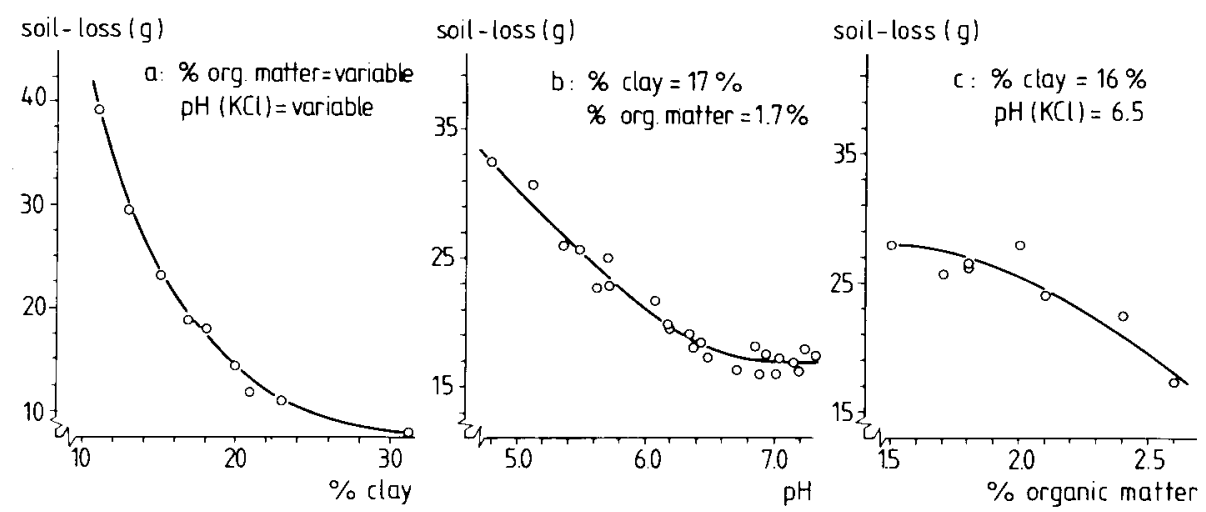

Fig. 3. Soil loss measured at different clay contents (a), $\mathrm{pH}(\mathrm{KCl})$ values (b) and organic matter contents (c) of the topsoil.

da Rocha, E.E. de Sagun, M. Oostrom and E.J. Henkens, who participated in the development of the equipment and the standard procedures. The technicians $S$. Maasland and W.J. Ackerman constructed and tested the prototypes of the apparatus.

\section{Availability of the rainfall simulator}

The standard equipment described is manufactured, under a royalty agreement with the Wageningen Agricultural University, by Eykelkamp Agrisearch Equipment b.v., Nijverheidsstraat 14, 6987 EM Giesbeek, Netherlands (Telegrams Eykelsoil Giesbeek NL, Telex 35416 Eykel NL, Phone 31-8336.1941). The equipment is delivered along with a more complete description of procedures for the use of the simulator in soil erosion and infiltration studies. An accessory is a soil box, in which soil samples can be packed for use of the simulator in the laboratory.

\section{Author's note}

Research workers involved in soil erodibility studies are requested to carry out the standard simulation test on soils for which the K-factor has been determined. Please communicate your results to the author of this paper, who is trying to relate the results obtained with the simulator to the soil erodibility factor of the universal soil loss equation. 


\section{References}

Adams, J.E., D. Kirkham \& D. Nielsen, 1957. A portable rainfall simulator-infiltrometer and physical measurements of soil in place. Proceedings Soil Science Society of America 21: 473-477.

Bergsma, E. \& C.R. Valenzuela, 1981. Drop testing aggregate stability of some soils near Merida, Spain. Earth Surface Processes and Landforms 6: 309-318.

Bergsma, E. \& A. Kamphorst, 1986. A simple field test for the assessment of soil erodibility. I. Description of the test and the results obtained. In: F. Callebout, D. Gabriels \& M. de Boodt (Eds.). Proceedings of the International Symposium on the Assessment of Soil Surface Sealing and Crusting (Ghent, 1985), p. 130-137. State University of Ghent and Flanders Research Centre for Soil Erosion and Soil Conservation, Ghent, Belgium.

Bryan, R.B., 1969. The development, use and efficiency of indices of soil erodibility. Geoderma 2: 5-26.

Gomez, K.A. \& A.A. Gomez, 1984. Statistical procedures for agricultural research. John Wiley and Sons, New York, 660 pp.

Kamphorst, A. \& E. Bergsma, 1986. A simple field test for the assessment of soil erodibility. II. Sensitivity and reproducibility of the test. In: F. Callebout, D. Gabriels \& M. de Boodt (Eds.). Proceedings of the International Symposium on the Assessment of Soil Surface Sealing and Crusting (Ghent, 1985), p. 138-145. State University of Ghent and Flanders Research Centre for Soil Erosion and Soil Conservation, Ghent, Belgium.

Low, A.J., 1954. The study of soil structure in the field and in the laboratory. Journal of Soil Science 5: 57-74.

Meyer, L.D. \& D.G. McCune, 1958. Rainfall simulator for run-off plots. Agricultural Engineering 39: 644-648.

Römkens, M.J.M., 1985. The Soil erodibility factor: a perspective. in: Soil erosion and conservation, p. 445-461. Soil Conservation Society of America, Ankeny, Iowa, USA.

Roth, C.B., T.W. Nelson \& M.J.M. Römkens, 1974. Prediction of subsoil erodibility using chemical, mineralogical and physical parameters. Environmental Protection Agency, Washington, DC, USA, $111 \mathrm{pp}$.

Wischmeier, W.H. \& D.D. Smith, 1960. A universal soil loss estimating equation to guide conservation farm planning. Proceedings 7th International Congress of Soil Science (Madison), Vol. 1, p. 418-425.

Wischmeier, W.H., C.B. Johnson \& B.V. Cross, 1971. A soil erodibility nomograph for farmland and construction sites. Journal of Soil and Water Conservation 26: 189-193.

Wischmeier, W.H. \& D.D. Smith, 1978. Predicting rainfall erosion losses. Agricultural Handbook 537. United States Department of Agriculture, Washington, DC, USA. 